\title{
Insulin Pump Settings During Breastfeeding in Women with Type 1 Diabetes
}

\author{
Sidse Kjærhus Nørgaard, MD, ${ }^{1,2}$ Kirsten Nørgaard, DMSC, ${ }^{3}$ Ann B. Roskjær, RD, ${ }^{1,2}$ \\ Elisabeth R. Mathiesen, $\mathrm{DMSC}^{1,2,4}$ and Lene Ringholm, MD, $\mathrm{PhD}^{1-3}$
}

\begin{abstract}
Background: We aimed to explore insulin pump settings in breastfeeding women with type 1 diabetes. Methods: Thirteen unselected breastfeeding women with type 1 diabetes on insulin pump therapy were included consecutively from April 2016 to October 2017. Blinded continuous glucose monitoring (CGM) for 6 days was applied at 1,2, and 6 months after delivery. Recommendations were intake of $210 \mathrm{~g}$ carbohydrate daily while aiming for glucose target range $4.0-10.0 \mathrm{mmol} / \mathrm{L}$ and avoiding hypoglycemia. Immediately after delivery a reduction of total insulin dose by $30 \%$ of the prepregnancy dose was recommended. Insulin pump target glucose was $5.8 \mathrm{mmol} / \mathrm{L}$.

Results: Median diabetes duration was 22 (range 13-36) years. At 1, 2, and 6 months, 13, 11, and 8 women, respectively, were breastfeeding and spent $\geq 70.8 \%$ (25\%-99\%) of time in the glucose target range and $\leq 3.8 \%$ $(0 \%-15.5 \%)$ of time with CGM $<4.0 \mathrm{mmol} / \mathrm{L}$ at night-time and for $24 \mathrm{~h}$. None of the women experienced severe hypoglycemia. HbAlc was $58(47-72) \mathrm{mmol} / \mathrm{mol}$ and $52(44-60)$ at 6 months and prepregnancy, respectively, $P=0.18$. At 1,2 , and 6 months, the insulin pump settings remained almost stable with basal insulin rates (at 03.00, 08.00, 12.00, and 18.00) 14\% lower and the carbohydrate-to-insulin ratios $10 \%$ higher than the prepregnancy settings.

Conclusions: In breastfeeding women with type 1 diabetes who consumed sufficient amounts of carbohydrates and obtained appropriate glycemic control, the basal insulin rates were 14\% lower and carbohydrate-to-insulin ratios $10 \%$ higher than before pregnancy. These data are useful when recommending insulin pump settings after delivery.
\end{abstract}

Keywords: Breastfeeding, Insulin pump therapy, Type 1 diabetes, Hypoglycemia, Carbohydrate counting, Continuous glucose monitoring.

\section{Introduction}

T HE USE OF modern diabetes technology as continuous glucose monitoring (CGM) and insulin pump therapy is becoming more prevalent. Among U.S. adults insulin pump (and CGM) use is higher in pregnant compared with nonpregnant women. ${ }^{1}$ Insulin pump therapy with rapid-acting insulin analog can lead to improved glycemic control in nonpregnant patients with type 1 diabetes, with a reduced prevalence of severe hypoglycemia compared with multiple daily injection therapy. ${ }^{2}$ However, cohort studies $^{3-5}$ and meta-analyses $^{6,7}$ in pregnant women with type 1 diabetes have not demonstrated that insulin pump therapy is superior to multiple daily injection therapy with regard to glycemic control or pregnancy outcomes.

Previously we demonstrated that breastfeeding women with type 1 diabetes, half of whom were on insulin pump therapy, spent significantly more time in the glucose target range $4-10 \mathrm{mmol} / \mathrm{L}$ than nonpregnant nonbreastfeeding women with type 1 diabetes. The prevalence of hypoglycemia was low in both groups and breastfeeding at night-time rarely induced hypoglycemia. ${ }^{8}$ The insulin doses were individually

\footnotetext{
${ }^{1}$ Center for Pregnant Women with Diabetes, Rigshospitalet, Copenhagen, Denmark.

${ }^{2}$ Department of Endocrinology, Rigshospitalet, Copenhagen, Denmark.

${ }^{3}$ Steno Diabetes Center Copenhagen, Gentofte, Denmark.

${ }^{4}$ The Institute of Clinical Medicine, Faculty of Health and Medical Sciences, University of Copenhagen, Copenhagen, Denmark.
} 
reduced immediately after delivery and the women consumed sufficient amounts of carbohydrate during daytime. ${ }^{8}$ In 2019, an international consensus group recommended that nonpregnant adults with diabetes using CGM spend $>70 \%$ of time in the range $3.9-10.0 \mathrm{mmol} / \mathrm{L}$ and $<4 \%$ of time $<3.9 \mathrm{mmol} / \mathrm{L}$. ${ }^{9}$

The insulin pump settings include the following five components: (1) basal insulin rates, (2) carbohydrate-toinsulin ratio, (3) insulin sensitivity factor, (4) target plasma glucose, and (5) insulin action time. ${ }^{10}$ The basal insulin rate, carbohydrate-to-insulin ratio, and insulin sensitivity factor can be different in the insulin pumps for the 24-h period. Bolus calculators are integrated parts of all insulin pumps and might be useful when estimating appropriate meal-time insulin dosing. ${ }^{10}$

During the first 2 months after delivery basal insulin requirements have been reported to be $36 \%$ lower in breastfeeding than in nonbreastfeeding women with type 1 diabetes on insulin pump therapy, but insulin pump settings or carbohydrate intake were not reported. ${ }^{11}$ To our knowledge no other study has evaluated insulin pump settings during breastfeeding in women with type 1 diabetes.

In this study we aimed to explore insulin pump settings in women with type 1 diabetes on insulin pump therapy during breastfeeding compared with insulin pump settings before pregnancy, to improve recommendations on expected insulin pump settings during breastfeeding.

\section{Methods}

This was an explorative study of 13 consecutive breastfeeding women with type 1 diabetes on insulin pump therapy who also participated in a previously published cohort study, ${ }^{8}$ which included 33 women with type 1 diabetes where hypoglycemia was investigated with intermittent CGM after delivery. This study was a secondary analysis and included all women on insulin pump therapy who were breastfeeding for at least 1 month after delivery and whose insulin pump uploads were available during breastfeeding. All 13 women delivered a single infant at department of obstetrics, Rigshospitalet from April 17, 2016 to October 22, 2017 and attended diabetes control at Steno Diabetes Center Copenhagen during pregnancy and after delivery.

All 13 women were treated with insulin pumps before pregnancy and continued this therapy throughout breastfeeding. They were trained in carbohydrate counting and used the bolus calculator to inform all boluses. The insulin pumps were Medtronic 554/754/640G $(n=9)$, Animas $(n=1)$, and Accu-chek Insight $(n=3)$ with rapid-acting insulin analog Aspart.

Blinded CGM (iPro ${ }^{\mathrm{TM}} 2$ Professional CGM; Medtronic, Northridge, CA) for 6 days was applied at 1 month (median 30 [range 21-41] days), 2 months (64 [50-103] days), and 6 months (173 [138-192] days) after delivery. The CGM device was inserted as per the manufacturer's guidelines into the subcutaneous tissue of the abdominal skin. The women were encouraged to continue normal daily living during each 6-day CGM recording period without changing breastfeeding, food, or exercise patterns. ${ }^{8}$ Capillary blood glucose was measured for calibration with a Contour ${ }^{\circledR}$ Next glucometer (Ascensia Diabetes Care Denmark Aps) 1 and $3 \mathrm{~h}$ after insertion. The women were recommended to perform at least four self-monitoring of plasma glucose (SMPG) measurements daily, before main meals and before bedtime. Target SMPG was $4.0-10.0 \mathrm{mmol} / \mathrm{L}^{8}$

Seven of the 13 women used CGM continuously, whereof 1 woman accepted to use additional Ipro CGM for this study. All routine CGM devices used Enlite2 sensors and the open CGM data of the remaining six women were used for analysis.

Based on the local treatment protocol, insulin pump settings immediately postpartum were individually tailored by an endocrinologist and estimated to $\sim 70 \%$ of prepregnancy insulin requirements. $^{8}$

From the insulin pump uploads the following insulin pump settings were recorded for the period immediately postpartum, at 1,2, and 6 months after delivery as well as 1 year before delivery: Basal insulin rates at 2 a.m., 5 a.m., 11 a.m., and 5 p.m., carbohydrate-to-insulin ratio and insulin sensitivity factor at 3 a.m., 8 a.m., 12 a.m., and 6 p.m. For each of these periods target plasma glucose and daily distribution between basal and bolus insulin were also registered.

The following CGM data at night-time and for 24-h were recorded: mean CGM values, percentage of time with CGM values in the target range $4.0-10.0 \mathrm{mmol} / \mathrm{L}$, hypoglycemia $<4.0 \mathrm{mmol} / \mathrm{L}$, and hyperglycemia $>10.0 \mathrm{mmol} / \mathrm{L}$.

After each 6-day CGM recording period, each woman discussed the downloaded CGM data with an endocrinologist (L.R.). Insulin pump settings and the diet were adjusted based on CGM data in combination with SMPG values focusing on obtaining most possible time in the target range 4.0 $10.0 \mathrm{mmol} / \mathrm{L}$ while avoiding hypoglycemia. The primary focus was on stable glycemia within the target range 4.0$10.0 \mathrm{mmol} / \mathrm{L}$ during night-time (11.00 p.m.-06.59 a.m.) with emphasis on the prevention of night-time hypoglycemia. Thereafter, hypoglycemia and pre- and postprandial glucose values during daytime (7.00 a.m.-10.59 p.m.) were evaluated with focus on average daily total carbohydrate intake and aiming for the same target glucose values. ${ }^{8}$

The women were recommended an individualized diabetes diet with a minimum daily total carbohydrate intake of $210 \mathrm{~g}$ in agreement with the Institute of Medicine guidelines to prevent ketonemia during breastfeeding. ${ }^{12}$ They were recommended to count carbohydrates from the main carbohydrate sources (bread, potatoes, rice, pasta, fruits, dairy products, and sweets) at all meals and snacks and to enter the amount of ingested carbohydrate into the insulin pump for insulin dosing, if the amount exceeded $5 \mathrm{~g}$.

During each 6-day CGM recording period the women were also encouraged to record self-estimated carbohydrate content from the main carbohydrate sources at all meals and snacks as well as self-estimated daily exercise in a food and exercise diary. ${ }^{8}$ The quantity of self-estimated carbohydrate intake from the main carbohydrate sources was calculated. When in doubt, the registered dietitian (A.B.R.) estimated the dimensions, weight and portion sizes based on validated tables. $8,13,14$

Mild hypoglycemia was defined as events with symptoms familiar to the woman as hypoglycemia and managed by herself. ${ }^{15}$ Severe hypoglycemia was defined as events requiring assistance from others to restore normal glucose levels. ${ }^{16}$

Data on daily breastfeeds in the previous week, number of daily formula feeds in the previous week, mild hypoglycemia in the previous week, severe hypoglycemia since delivery, and smoking were derived from questionnaires filled in at 1,2 , and 6 months. ${ }^{17}$ 
Table 1. Baseline Characteristics in 13 Breastfeeding Women With Type 1 Diabetes ON INSUlin PUMP THERAPY

\begin{tabular}{lc}
\hline Age, years & $31(24-40)$ \\
Duration of diabetes, years & $22(13-36)$ \\
Nordic origin & $13(100)$ \\
Nulliparity & $9(69)$ \\
BMI before pregnancy, $\mathrm{kg} / \mathrm{m}^{2}$ & $26.5(21.0-31.7)$ \\
HbA1c before pregnancy, mmol/mol & $52(44-60)$ \\
Gestational weight gain, $\mathrm{kg}$ & $14.2(5.8-20.4)$ \\
Routine use of continuous & $7(54)$ \\
$\quad$ glucose monitoring &
\end{tabular}

Data are given as $n(\%)$ or median (range).

BMI, body mass index.

Full or predominant breastfeeding was defined as $\geq 6$ breastfeeds daily. ${ }^{8,18}$ Gestational weight gain was calculated as the difference between the last weight measured before delivery and the self-reported prepregnancy weight. ${ }^{19}$ Postpartum weight retention was defined as weight at one, two and six months after delivery, respectively, compared with prepregnancy weight. ${ }^{20}$

HbA1c was measured by a TOSOH G8 Automated Glycohemoglobin Analyzer (Tosoh Corporation, Tokyo).

The study participants gave written informed consent to participate. The research protocol was approved by the $\mathrm{Re}$ gional Committee on Biomedical Research Ethics (Protocol No. H-16016397), the Danish Data Protection Agency (Protocol No. 2012-58-0004) and registered within ClinicalTrials.gov (NCT02898428), and carried out in accordance with the Declaration of Helsinki (2008).

\section{Statistical analysis}

Data were non-normally distributed and were given as median (range or interquartile range). Categorical data were given as $n(\%)$.
HbA1c values at 6 months after delivery were compared with prepregnancy values by using related samples Wilcoxon signed rank test.

As this was an explorative study, a power calculation was not possible.

A two-sided $P$-value $<0.05$ was regarded as statistically significant. The statistical analyses were performed using SPSS version 25 (IBM Corporation, Armonk, NY).

\section{Results}

Baseline characteristics and pregnancy outcomes are given in Table 1. Median age was 31 (range 24-40) years and diabetes duration was $22(13-36)$ years.

At 1, 2, and 6 months after delivery, uploaded data on insulin pump settings were available in 13,11 , and 8 women, respectively. One woman discontinued breastfeeding after insulin pump upload, but immediately before scheduled application of CGM at 1 month leaving CGM data available in 12,11 , and 8 women, respectively.

At all CGM recording periods the median percentage of time spent in the target range $4.0-10.0 \mathrm{mmol} / \mathrm{L}$ was $\geq 70.8 \%$, whereas the women spent no more than $3.8 \%$ of time with $\mathrm{CGM}<4.0 \mathrm{mmol} / \mathrm{L}$ both for $24 \mathrm{~h}$ and during night-time only, with large interindividual variations (Table 2). The majority of women spent $<4 \%$ of time with glucose $<4.0 \mathrm{mmol} / \mathrm{L}$, but up to $15.5 \%$ of time spent in hypoglycemia was seen (Table 2).

The pump settings immediately after delivery were modified by the patients within the first month after delivery and remained almost stable thereafter with basal insulin rates (at 3 a.m., 8 a.m., 12 p.m. and 6 p.m.) 14\% lower (Fig. 1) and the carbohydrate-to-insulin ratios $\sim 10 \%$ higher than the prepregnancy settings (Fig. 2). During breastfeeding the insulin sensitivity factor was 3.5 and target plasma glucose was $5.8 \mathrm{mmol} / \mathrm{L}$.

Table 2. Continuous Glucose Monitoring Data in Breastfeeding Women with Type 1 Diabetes AT 1, 2, AND 6 Months After Delivery

\begin{tabular}{|c|c|c|c|}
\hline & $\begin{array}{l}1 \text { Month after } \\
\text { delivery }\end{array}$ & $\begin{array}{l}2 \text { Months after } \\
\text { delivery }\end{array}$ & $\begin{array}{l}6 \text { Months after } \\
\text { delivery }\end{array}$ \\
\hline Number & 12 & 11 & 8 \\
\hline Full or predominant breastfeeding ( $\geq 6$ breastfeedings daily) & $12(100)$ & $10(91)$ & $8(100)$ \\
\hline Days after delivery & $31(25-41)$ & $64(50-103)$ & $173(138-192)$ \\
\hline Mean glucose at night-time, $\mathrm{mmol} / \mathrm{L}$ & $8.0(5.8-11.1)$ & $8.4(6.5-12.8)$ & $8.6(7.5-10.8)$ \\
\hline $\begin{array}{l}\text { Percentage time spent with glucose }>10.0 \mathrm{mmol} / \mathrm{L} \\
\text { at night-time }\end{array}$ & $24.5(3.9-55.0)$ & $13.1(0.0-75.5)$ & $19.8(14.0-54.2)$ \\
\hline $\begin{array}{l}\text { Percentage time spent in target range } \\
\quad 4.0-10.0 \mathrm{mmol} / \mathrm{L} \text { at night-time }\end{array}$ & $73.8(45.4-92.0)$ & $80.2(24.6-99.3)$ & $78.8(43.1-83.3)$ \\
\hline $\begin{array}{l}\text { Percentage time spent with glucose } \\
<4.0 \mathrm{mmol} / \mathrm{L} \text { at night-time }\end{array}$ & $1.2(0.0-13.6)$ & $1.4(0.0-15.5)$ & $1.7(0.0-3.0)$ \\
\hline $\begin{array}{l}\text { Number of women spending }<4 \% \text { of time with glucose } \\
<4.0 \mathrm{mmol} / \mathrm{L} \text { at night-time }\end{array}$ & $10(77)$ & $9(82)$ & $8(100)$ \\
\hline Mean glucose for $24 \mathrm{~h}, \mathrm{mmol} / \mathrm{L}$ & $8.3(5.7-10.4)$ & $8.6(6.8-11.8)$ & $8.2(7.3-11.3)$ \\
\hline Percentage time spent with glucose $>10.0 \mathrm{mmol} / \mathrm{L}$ for $24 \mathrm{~h}$ & $25.0(4.1-47.5)$ & $25.6(5.5-72.0)$ & $26.8(16.1-59.4)$ \\
\hline $\begin{array}{l}\text { Percentage time spent in target range } 4.0-10.0 \mathrm{mmol} / \mathrm{L} \\
\text { for } 24 \mathrm{~h}\end{array}$ & $71.5(52.5-87.7)$ & $71.7(27.1-89.3)$ & $70.8(39.1-82.5)$ \\
\hline Percentage time spent with glucose $<4.0 \mathrm{mmol} / \mathrm{L}$ for $24 \mathrm{~h}$ & $3.8(0.0-13.6)$ & $1.7(0.0-6.8)$ & $1.8(0.0-3.9)$ \\
\hline $\begin{array}{l}\text { Number of women spending }<4 \% \text { of time with glucose } \\
<4.0 \mathrm{mmol} / \mathrm{L} \text { for } 24 \mathrm{~h}\end{array}$ & $7(54)$ & $8(73)$ & $8(100)$ \\
\hline
\end{tabular}

Data are given as $n(\%)$ or median (range). Night-time was defined as 11.00 p.m.-06.59 a.m. 


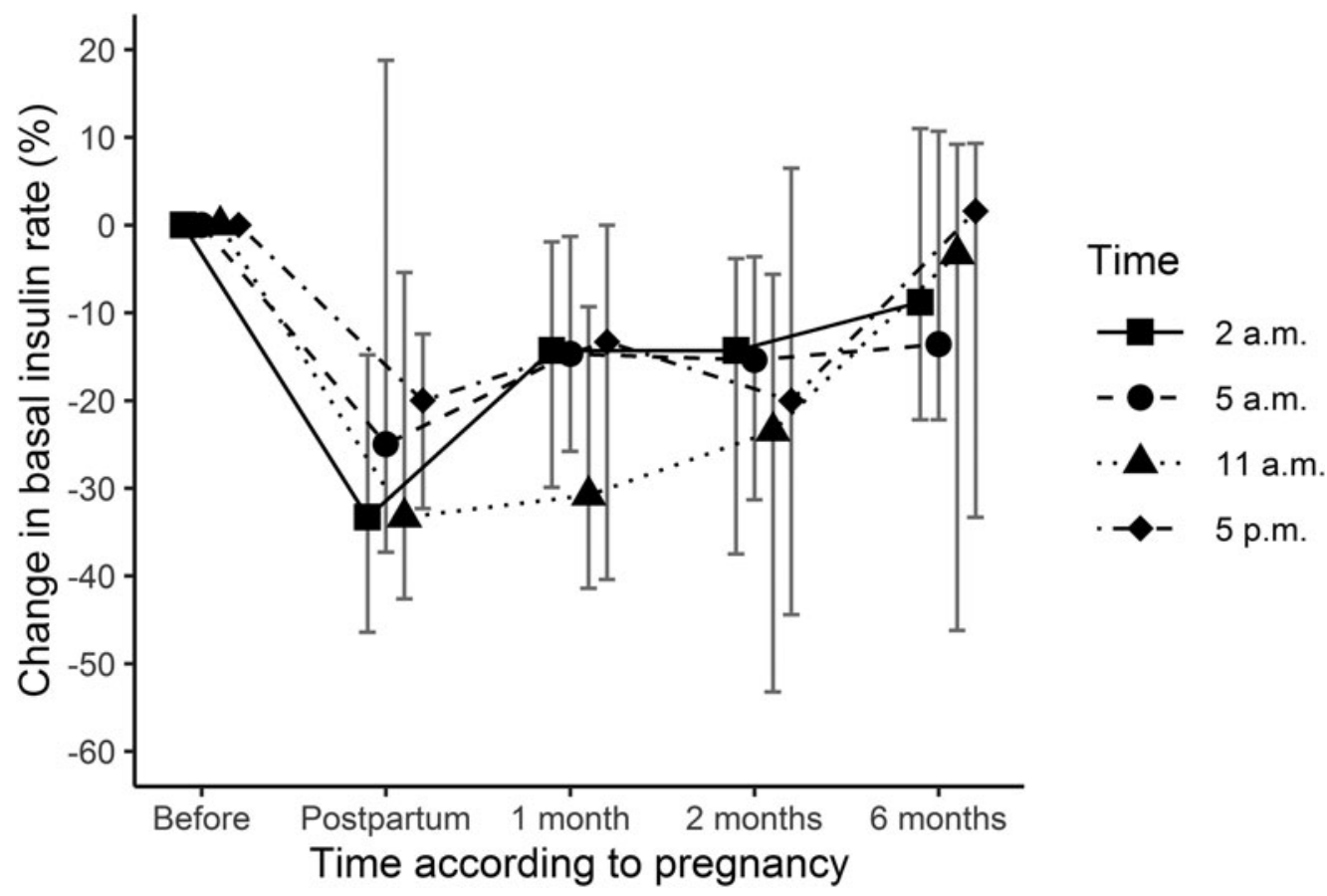

FIG. 1. Changes in basal insulin rate in 13 women with type 1 diabetes from 1 year before delivery to the breastfeeding period immediately postpartum and at 1,2 , and 6 months after delivery (median [interquartile range]).

The basal insulin infusion constituted approximately half of total daily insulin dose before and during breastfeeding (Table 3). The time intervals for basal insulin rates and carbohydrate-to-insulin ratios varied individually but were often similar to the time intervals before pregnancy (data not shown).
During breastfeeding and 1 year before delivery, insulin action time was set to $4.0 \mathrm{~h}$ in all women except one.

In the three CGM recording periods after delivery, eight women did not change basal rate temporarily, did not have any suspension before or on low glucose values, or did not have the last two functionalities available. The remaining five

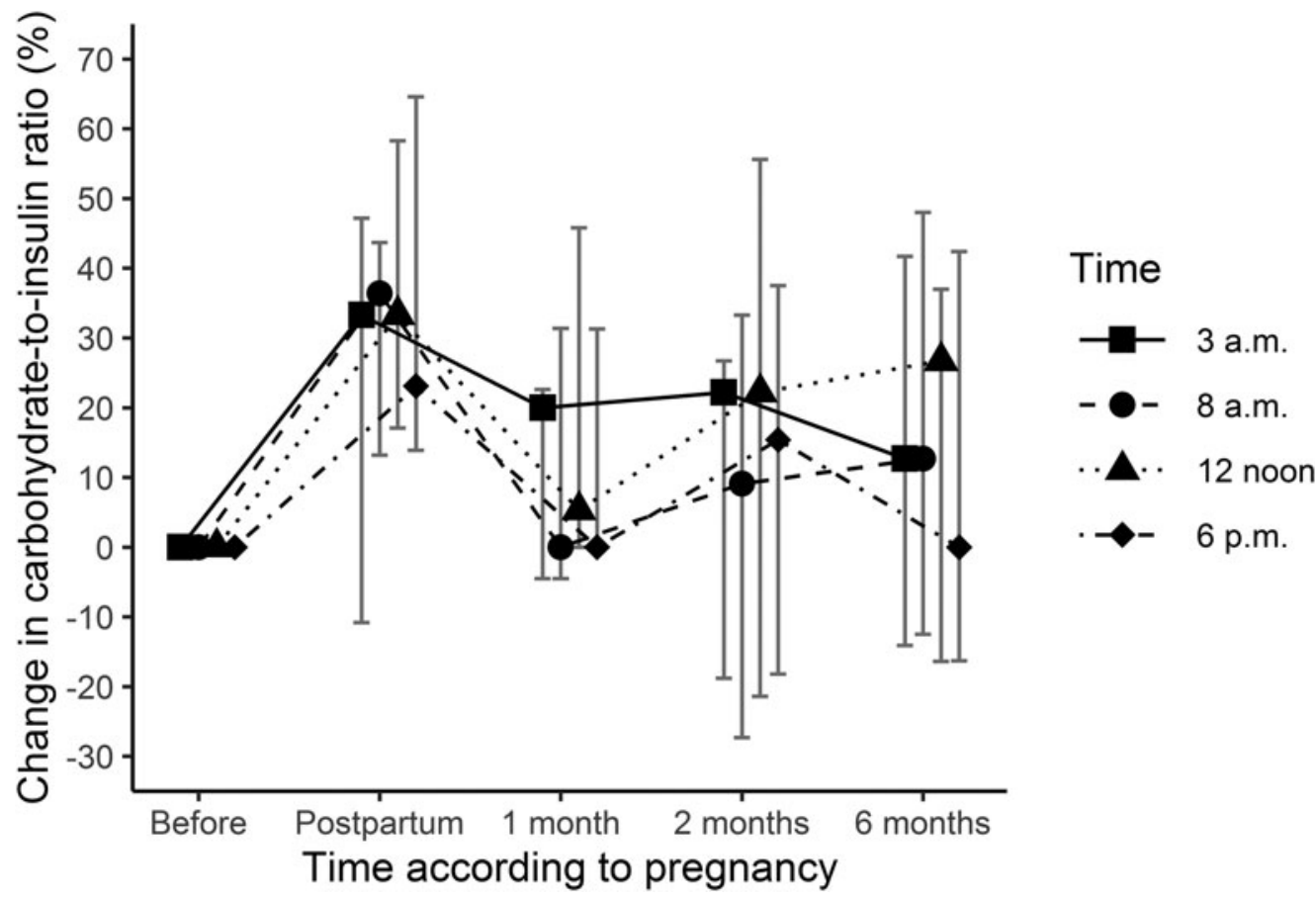

FIG. 2. Changes in carbohydrate-to-insulin ratio in 13 women with type 1 diabetes from 1 year before delivery to the breastfeeding period immediately postpartum and at 1,2, and 6 months after delivery (median [interquartile range]). 
Table 3. Glycemic Control and Carbohydrate Intake in Women with Type 1 Diabetes 1 Year Before Delivery and During Breastfeeding at 1, 2, and 6 Months after Delivery

\begin{tabular}{|c|c|c|c|c|}
\hline & $\begin{array}{l}1 \text { Year before } \\
\text { delivery }\end{array}$ & $\begin{array}{l}1 \text { Month after } \\
\text { delivery }\end{array}$ & $\begin{array}{l}2 \text { Months after } \\
\text { delivery }\end{array}$ & $\begin{array}{l}6 \text { Months after } \\
\text { delivery }\end{array}$ \\
\hline Number & 13 & 13 & 11 & 8 \\
\hline $\mathrm{HbAlc}, \mathrm{mmol} / \mathrm{mol}$ & $52(44-60)$ & $48(39-56)$ & $53(43-62)$ & $58(47-72)$ \\
\hline Insulin, total daily dose, IU/24 h & $38(22-66)^{\mathrm{a}}$ & $30(25-44)$ & $32(27-47)$ & $33(29-41)$ \\
\hline Total insulin dose, IU/kg & $0.5(0.3-0.8)^{\mathrm{a}}$ & $0.4(0.3-0.6)$ & $0.4(0.4-0.7)$ & $0.5(0.4-0.5)^{\mathrm{a}}$ \\
\hline $\begin{array}{l}\text { Basal insulin dose, IU/kg, } \\
1 \text { year before delivery: }\end{array}$ & $0.34(0.10-0.40)$ & $0.22(0.10-0.36)$ & $0.19(0.12-0.35)$ & $0.21(0.14-0.30)$ \\
\hline $\begin{array}{l}\text { Basal insulin, percentage } \\
\text { of total daily insulin dose (\%) }\end{array}$ & $58(33-79)^{\mathrm{a}}$ & $58(30-78)$ & $49(28-73)$ & $48(31-62)^{\mathrm{a}}$ \\
\hline $\begin{array}{l}\text { Daily amount of carbohydrate } \\
\text { entered in the insulin pump }\end{array}$ & $99(20-255)^{\mathrm{a}}$ & $124(50-206)^{\mathrm{a}}$ & $150(37-184)^{\mathrm{a}}$ & $150(43-212)^{\mathrm{a}}$ \\
\hline $\begin{array}{l}\text { Number of episodes of mild } \\
\text { hypoglycemia in the previous week }\end{array}$ & - & $3.5(0-14)$ & $2.0(0-10)$ & $2.0(0-4)$ \\
\hline Weight, $\mathrm{kg}$ & $73.0(62.5-87.7)^{\mathrm{b}}$ & $79.2(65.9-85.2)$ & $76.6(65.2-84.5)$ & $72.1(66.1-83.6)$ \\
\hline Postpartum weight retention, $\mathrm{kg}$ & - & $1.5(-4.1$ to 8.1$)$ & $-0.3(-3.3$ to 7.3$)$ & $-2.9(-5.0$ to 7.8$)$ \\
\hline
\end{tabular}

Data are given as $n(\%)$ or median (range).

${ }^{a}$ Data were available in $62 \%-91 \%$ of women.

${ }^{\mathrm{b}}$ Last recorded weight before pregnancy.

women used lower temporary basal rate, suspension before/on low glucose values or both during 37 out of 87 (43\%) registered nights.

Data on self-estimated daily amounts of carbohydrate recorded in food and exercise diaries were available in seven women. The women entered on average up to $20 \mathrm{~g}$ carbohydrate less in the insulin pumps than they recorded in the food and exercise diaries, but overall this difference was insignificant (data not shown). Data on self-estimated daily exercise were available in five women. The women reported median 41, 57, and $41 \mathrm{~min}$ of daily exercise at 1,2, and 6 months, respectively (data not shown).

$\mathrm{HbA1c}$ at 6 months was comparable with prepregnancy HbA1c (58 [47-72] mmol/mol and 52 [44-60], respectively, $P=0.18)$.

In the study period none of the women experienced severe hypoglycemia and none were smoking.

\section{Conclusions}

In this prospective explorative study, unselected women with long-term type 1 diabetes on insulin pump therapy maintained good glycemic control with a low prevalence of hypoglycemia during breastfeeding. On average basal insulin rates were $14 \%$ lower and carbohydrate-to-insulin ratios were $10 \%$ higher than prepregnancy settings.

The women had documented good glycemic control with $\geq 70.8 \%$ of the time in target range and $\leq 3.8 \%$ of time below target range both at night-time and for $24 \mathrm{~h}$. However, in few women up to $15.5 \%$ of time spent in hypoglycemia was seen. These findings are in agreement with new recommendations of appropriate glycemic control advocating time in range $>70 \%$ of time and time spent in hypoglycemia $<4 \%$ of time. ${ }^{9}$ It is reassuring that none of the women experienced severe hypoglycemia, and on average mild hypoglycemia occurred twice weekly with an appropriate $\mathrm{HbA1c}$ level.

In this study with documented good glycemic control, the insulin pump settings remained mostly stable from 1 to 6 months after delivery with basal infusion rates $14 \%$ lower compared with prepregnancy settings and rare use of tempo- rarily reduced basal infusion rates or suspension of basal insulin infusion before or on low. The present reduction in basal infusion rates was less pronounced than the previously reported reduction of 36\%. ${ }^{11}$ On average the reported carbohydrate intake in this study was close to the recommended daily amount during breastfeeding. ${ }^{12}$ The daily amount of carbohydrate entered in the insulin pumps at 2 and 6 months was $\sim 50 \%$ higher than the carbohydrate amount entered before pregnancy, and still the total daily insulin dose during breastfeeding was lower than before pregnancy. Whether this focus on sufficient daily carbohydrate intake contributes to the minor reduction in basal infusion rate and low prevalence of night-time hypoglycemia remains speculative. However, if the goals for sufficient daily carbohydrate intake are not met, a larger decline in basal infusion rate is possibly needed. In contrast, a higher rate of hypoglycemia would be expected if the insulin pump settings were at the same level as the prepregnancy insulin pump settings.

Data in the literature on insulin pump settings during breastfeeding was not identified.

All women in this study were already treated with insulin pumps before pregnancy and were, therefore, familiar with carbohydrate counting and the device during pregnancy and after delivery. Women tended to enter lower amounts of carbohydrate in the insulin pumps than that they recorded in the food diaries, but the numbers were too small for conclusions. However, it is a clinical experience that insulin pump users do not necessarily enter all ingested carbohydrates in the insulin pump, in particular when consuming carbohydrates to prevent or treat hypoglycemia and when eating large meals. ${ }^{21}$ The number of women reporting amount of daily exercise was low, but the reported amount of exercise was on the same level as in the previously published whole cohort of breastfeeding women with type 1 diabetes. ${ }^{8}$

In this study, the same endocrinologist reviewed the CGM data and adjusted the insulin pump settings accordingly in collaboration with the women at each consultation.

Despite interindividual variations, the present observation of $14 \%$ lower basal infusions rates and $10 \%$ higher carbohydrate-to-insulin ratios during breastfeeding are 
probably useful when recommending insulin pump settings after delivery. Further studies are needed to explore whether the target plasma glucose at $5.8 \mathrm{mmol} / \mathrm{L}$, insulin sensitivity factor at 3.5, and insulin action time of $4.0 \mathrm{~h}$, as used in this study, are optimal in the breastfeeding period among women with type 1 diabetes.

It is important to prevent maternal hypoglycemia within the first days after delivery where carbohydrate intake often is insufficient. In addition, a recent study suggests that insulin sensitivity is higher within the first few days after delivery compared with 2 months after delivery. ${ }^{22}$ Our local strategy was to reduce the daily insulin dose to $\sim 70 \%$ of prepregnancy insulin requirements immediately after delivery. ${ }^{8}$ The observation that the women gradually changed their pump settings within the first weeks after delivery and thereby increased the daily insulin dose is probably related to sufficient carbohydrate intake and a small physiological change in the insulin sensitivity. Unfortunately, we do not have CGM data for the period immediately after delivery and our local practice of adjusting the insulin pump settings immediately postpartum to $\sim 70 \%$ of prepregnancy insulin requirements needs to be evaluated in future studies. Data on carbohydrate intake were not collected during pregnancy.

It is a strength that this study includes structured evaluation of prospectively collected uploaded data on insulin pump settings during breastfeeding and before pregnancy in unselected breastfeeding women with documented adequate carbohydrate intake, glycemic control, and modest postpartum weight retention.

One woman discontinued breastfeeding before CGM application at 1 month. Data on her insulin pump settings in the previous week were included in this study as they were judged to be representative for her diabetes regulation during breastfeeding. At 6 months, 8 out of $13(62 \%)$ women were fully breastfeeding. We have previously reported that $49 \%$ of women with type 1 diabetes at our center fully breastfeed at 4 months after delivery. ${ }^{23}$ Nonetheless, we acknowledge that the low number of women included in this study and the high dropout rate due to discontinuation of breastfeeding are limitations. HbA1c at 6 months after delivery was comparable with HbA1c before pregnancy, but due to the low number of women, the $P$-value should be interpreted with caution.

We registered basal insulin rates and carbohydrate-toinsulin ratios at four time points. However, the time intervals for these settings varied from woman to woman but were often similar to the prepregnancy time intervals.

Future studies, including larger numbers of women and the period immediately after delivery, are needed to improve the guidance of the individual woman on the expected insulin pump settings immediately after delivery and during breastfeeding.

To conclude, in this exploratory study of breastfeeding women with type 1 diabetes with documented sufficient carbohydrate intake and appropriate glycemic control, on average the basal insulin rates were $14 \%$ lower and carbohydrate-toinsulin ratios $10 \%$ higher than prepregnancy settings. These data are useful when recommending insulin pump settings after delivery until further studies are available.

\section{Duality of Interests}

E.R.M. and L.R. are participating in clinical studies on the use of insulin in pregnant women with pre-existing diabetes in collaboration with Novo Nordisk, no personal honorarium is involved. E.R.M. is in speaker's bureau of Novo Nordisk. K.N. serves as adviser to Sanofi, Medtronic, Abbott, and Novo Nordisk; owns shares in Novo Nordisk; has received research grants from Novo Nordisk and Roche Diabetes Care; and has received fees for speaking from Medtronic, Roche Diabetes Care, Rubin Medical, Sanofi, Novo Nordisk, Zealand Pharma, and Bayer. S.K.N. and A.B.R. declare no duality of interest associated with this article.

\section{Author Disclosure Statement}

No competing financial interests exist.

\section{Funding Information}

No funding was received for this article.

\section{References}

1. Polsky S, Wu M, Bode BW, et al.: Diabetes technology use among pregnant and nonpregnant women with T1D in the T1D exchange. Diabetes Technol Ther 2018;20:517-523.

2. Pickup JC, Renard E: Long-acting insulin analogs versus insulin pump therapy for the treatment of type 1 and type 2 diabetes. Diabetes Care 2008;31(Suppl 2):S140-S145.

3. Abell SK, Suen M, Pease A, et al.: Pregnancy outcomes and insulin requirements in women with type 1 diabetes treated with continuous subcutaneous insulin infusion and multiple daily injections: cohort study. Diabetes Technol Ther 2017;19:280-287.

4. Kallas-Koeman MM, Kong JM, Klinke JA, et al.: Insulin pump use in pregnancy is associated with lower HbA1c without increasing the rate of severe hypoglycaemia or diabetic ketoacidosis in women with type 1 diabetes. Diabetologia 2014;57:681-689.

5. Mathiesen JM, Secher AL, Ringholm L, et al.: Changes in basal rates and bolus calculator settings in insulin pumps during pregnancy in women with type 1 diabetes. J Matern Fetal Neonatal Med 2014;27:724-728.

6. Farrar D, Tuffnell DJ, West J, West HM: Continuous subcutaneous insulin infusion versus multiple daily injections of insulin for pregnant women with diabetes. Cochrane Database Syst Rev 2016;CD005542. DOI: 10.1002/ 14651858.CD005542.pub3.

7. Rys PM, Ludwig-Slomczynska AH, Cyganek K, Malecki MT: Continuous subcutaneous insulin infusion vs multiple daily injections in pregnant women with type 1 diabetes mellitus: a systematic review and meta-analysis of randomised controlled trials and observational studies. Eur J Endocrinol 2018;178:545-563.

8. Ringholm L, Roskjaer AB, Engberg S, et al.: Breastfeeding at night is rarely followed by hypoglycaemia in women with type 1 diabetes using carbohydrate counting and flexible insulin therapy. Diabetologia 2019;62:387-398.

9. Battelino T, Danne T, Bergenstal RM, et al.: Clinical targets for continuous glucose monitoring data interpretation: recommendations from the international consensus on time in range. Diabetes Care 2019;42:1593-1603.

10. Schmidt S, Norgaard K: Bolus calculators. J Diabetes Sci Technol 2014;8:1035-1041.

11. Riviello C, Mello G, Jovanovic LG: Breastfeeding and the basal insulin requirement in type 1 diabetic women. Endocr Pract 2009;15:187-193.

12. Dietary Reference Intakes for Energy, Carbohydrate, Fiber, Fat, Fatty Acids, Cholesterol, Protein and Amino Acids 
(Macronutrients). 2005. www.nap.edu/read/10490/chapter/ 1 (accessed July 19, 2019).

13. Vitakost-professional diet calculation. 2018. https://www .vitakost.dk/en/home (accessed July 19, 2019).

14. Technical University of Denmark. Dimensions, weight and portion sizes of foods. 2013. www.food.dtu.dk/english/-/media/ Institutter/Foedevareinstituttet/Publikationer/Pub-2013/ Rapport_Maal-vaegt-og-portionsstoerrelser-paa-foedevarer .ashx?la=da (accessed July 19, 2019).

15. Pedersen-Bjergaard U, Pramming S, Thorsteinsson B: Recall of severe hypoglycaemia and self-estimated state of awareness in type 1 diabetes. Diabetes Metab Res Rev 2003;19: 232-240.

16. Seaquist ER, Anderson J, Childs B, et al.: Hypoglycemia and diabetes: a report of a workgroup of the American Diabetes Association and the Endocrine Society. Diabetes Care 2013; 36:1384-1395.

17. Stage E, Norgard H, Damm P, Mathiesen E: Long-term breast-feeding in women with type 1 diabetes. Diabetes Care 2006;29:771-774.

18. Achong N, McIntyre HD, Callaway L, Duncan EL: Glycaemic behaviour during breastfeeding in women with Type 1 diabetes. Diabet Med 2016;33:947-955.

19. Jensen DM, Damm P, Sorensen B, et al.: Pregnancy outcome and prepregnancy body mass index in 2459 glucosetolerant Danish women. Am J Obstet Gynecol 2003;189: 239-244.
20. Vinter CA, Jensen DM, Ovesen P, et al.: Postpartum weight retention and breastfeeding among obese women from the randomized controlled Lifestyle in Pregnancy (LiP) trial. Acta Obstet Gynecol Scand 2014;93:794-801.

21. Smart CE, Ross K, Edge JA, et al.: Can children with Type 1 diabetes and their caregivers estimate the carbohydrate content of meals and snacks? Diabet Med 2010; 27:348-353.

22. Waters TP, Kim SY, Werner E, et al.: Should women with gestational diabetes be screened at delivery hospitalization for type-2 diabetes? Am J Obstet Gynecol 2019. [Epub ahead of print]; DOI: 10.1016/j.ajog.2019.07.035.

23. Herskin CW, Stage E, Barfred C, et al.: Low prevalence of long-term breastfeeding among women with type 2 diabetes. J Matern Fetal Neonatal Med 2016;29:2513-2518.

Address correspondence to: Sidse Kjarhus Nфrgaard, MD Center for Pregnant Women with Diabetes Rigshospitalet Blegdamsvej 9 Copenhagen 2100 Denmark

E-mail: sidsenorgaard@hotmail.com 